Psychology of Language and Communication 2013, Vol. 17, No. 2

VERSITAOPEN

DOI: $10.2478 /$ plc-2013-0012

\author{
NIRNAY KUMAR KESHREE ${ }^{1}$, SUMAN KUMAR ${ }^{1}$, SHRIYA BASU ${ }^{1}$, \\ MADHUSHREE CHAKRABARTY ${ }^{2}$, THOMAS KISHORE ${ }^{3}$ \\ ${ }^{1}$ Ali Yavar Jung National Institute for the Hearing Handicapped, ERC, Kolkata \\ ${ }^{2}$ Bangur Institute of Neurosciences, Kolkata \\ ${ }^{3}$ University of Hyderabad
}

\title{
ADAPTATION OF THE WESTERN APHASIA BATTERY IN BANGLA
}

\begin{abstract}
Aphasia following an acquired neurological insult necessitates an in-depth evaluation of the primary and secondary language symptoms. Of all the tools available for aphasia diagnosis, the Western Aphasia Battery (WAB; Kertesz, 1982) has proved to be one of the most comprehensive test batteries for describing the aphasia symptom complex. Several authors have pointed out the need for language-specific tools for the assessment of aphasia. But in Bengali, the most prevalent language in eastern India, no formal language assessment tool was available to date. The present study adapted the original WAB in Bengali to give the Bengali WAB (B-WAB). The study was completed in three phases: development, standardization and validation of the B-WAB. The test material was developed preserving the total number of items, however minor changes were made wherever necessary so that it matched the sociolinguistic norms in this part of the country. It was standardized in a group of 150 normal individuals in five different age groups ranging from 18-70 years, and normative values were provided for each subtest for each group. For establishing validity, it was administered to 30 aphasic subjects and the results indicated that the B-WAB was a valid tool for testing individuals with aphasia.
\end{abstract}

Key words: aphasia, Bengali, WAB

\section{Introduction}

Aphasia is an acquired communication disorder caused by brain damage that impairs a person's ability to understand, produce and use language (La Pointe, 2005). Furthermore, it is a multimodal disorder which includes additional neurological impairments such as apraxia of speech or dysarthria (Chapey, 1994).

Address for correspondence: Suman Kumar, Dept. of Speech Language Pathology, Ali Yavar Jung National Institute for the Hearing Handicapped, ERC, B.T. Road, Bon Hooghly, Kolkata-700090, India. E-mail: sumannihh@gmail.com 
The presentation of aphasic symptoms is seen secondary to brain damage such as stroke (most frequently), traumatic brain injury, and degenerative diseases (Murray \& Chapey, 2001). A patient with aphasia may present impairment in any area of the production, comprehension and several other aspects of language. Aphasia can be classified into several types based on its symptom complex, but its major components of deficits revolve around oral production, reading, writing and auditory comprehension (Kertesz, 1982).

One and a quarter century of intensive analysis of aphasic symptoms has produced considerable consensus on identifiable component deficits, some of which may appear in nearly pure form, while others stand out by their severity against a background of milder impairments in the remaining language skills. Thus, one may find severe, extremely selective disorders of auditory comprehension, object naming, articulation, reading or repetition (Kertesz, 1982). In some respects, major component deficits in aphasia correspond to the major channels of language in everyday parlance: oral production, reading, writing, auditory comprehension. But within each of these domains, the deficits are distinctive and unique. Therefore, the language deficits in aphasia cannot be based against either normal language performance or the developmental pattern seen in children; rather, they are empirically derived from systematic observation of patients with aphasia (Kertesz, 1982). The objective evaluation of these characteristics and differentiation of cardinal features would help in differential diagnosis of aphasia.

Based on the myriad of symptoms, classification of aphasia has been a matter of significant interest among researchers, as a result of which several classification systems have existed from the early 19 th century to date, representing divergent ideas reflecting a difference in perspective. However, the classification scheme of Goodglass and Kaplan (1972) is currently used (Sarno, 2002; McNeil \& Copland; 2011). Goodglass and Kaplan (1972) outlined the following major classification for assessing adults with aphasia such as Broca's aphasia, Wernicke's aphasia, anomic aphasia, global aphasia, conduction aphasia, transcortical sensory aphasia, pure word deafness, mixed nonfluent aphasia.

Aphasia test batteries have been used by clinicians to assess persons with aphasia (PWA) for nearly a century. As interest in aphasia rehabilitation grew between 1960 and 1982, and objective measures were needed to measure the effects of treatment, several test batteries were developed which have a widespread use globally (Byng et al., 1990). Among them are the Minnesota Test for Differential Diagnosis of Aphasia (MTDDA; Schuell, 1972), the Porch Index of Communicative Ability (PICA; Porch, 1981), the Boston Diagnostic Aphasia Examination (BDAE; Goodglass \& Kaplan, 1983), and the Western Aphasia Battery (WAB; Kertesz, 1982).

The Western Aphasia Battery (Kertesz, 1982) provides the diagnostic goals of classifying aphasia subtypes and rating the severity of aphasic impairment. The test has been used in taxonomic classification studies (Kertesz, 1976; Kertesz \& Phipps, 1977, 1980) and in the description of recovery from aphasia (Lomas \& 
Kertesz, 1978). The test presents itself as a comprehensive aphasia battery which provides highly structured observations to arrive at a diagnosis.

Language abilities even among normal individuals can be varied depending on gender, age, educational level, and so forth. For example, the effect of literacy on cognitive abilities including language has been reported (Manly et al., 1999). Age also has a significant influence on language abilities such as vocabulary diversity, sentence complexity, subordinating conjunctions, and possibly sentence length (Bromley, 1991). Therefore, aphasia being an acquired language disorder, careful consideration in linguistic assessment is a key feature from the point of view of diagnostics and there are several factors affecting the outcome of the tests. The variables affecting the outcome multiply when dealing with the problem of the growing number of aphasics in different parts of the world speaking their own native language and the standardized assessment tool being available only in English. This has not only affected the diagnostic scenario but has also presented itself as a major shortcoming in the process of service delivery.

The Western Aphasia Battery (Kertesz, 1982) is a widely used tool for assessment of aphasia and has been adapted to different languages globally. It has been translated: a Japanese version has been published (WAB Aphasia Test Construction Committee, 1986); a Hebrew and Korean version of the WAB has also been reported by Kasher et al. (1999), Zaidel et al. (2000) and Kim and Na (2004), respectively. An adapted version of the WAB is also available in a few of the Indian languages, e.g. the Kannada version of the Western Aphasia Battery (Chengappa \& Kumar, 2008), the Telugu version of the Western Aphasia Battery (Pallavi, 2010) and the test of aphasia in Malayalam (Jenny, 1992). However, so farthere are no standardized tools for evaluating the increasing number of Bengali-speaking persons with aphasia in India and other Bengali communities around the world. Bengali or Bangla is native to the region of eastern South Asia known as Bengal, which comprises present-day Bangladesh, the Indian state of West Bengal, and parts of the Indian states of Tripura and Assam. With nearly 193 million speakers in total, Bengali is one of the most widely spoken languages, ranking seventh among the most widely spoken languages in the world.

The goals of this study were: a) to develop and standardize the WAB in Bengali $(B-W A B), b)$ to find out age- and gender-specific normative values for the $\mathrm{B}-\mathrm{WAB}, \mathrm{c})$ to check for the construct validity of the test by testing the B-WAB on persons with aphasia.

\section{Method}

\section{Participants}

The control group consisted of 150 healthy normal individuals between the ages of 18 and 70 years. This age range was further stratified into the following groups, with 30 participants in each group: 18 to 30 years, 31 to 40 years, 41 to 
Table 1. Summary of the participants with aphasia

\begin{tabular}{|c|c|c|c|c|}
\hline & Gender & Age & Education level & Site of lesion \\
\hline 1 & male & 56 & graduate & $\begin{array}{l}\text { Left posterior frontal acute infarct } \\
\text { (pre-Rolandic MCA territory) }\end{array}$ \\
\hline 2 & male & 50 & secondary & Subacute infarct seen in both parietal cortex \\
\hline 3 & male & 51 & postgraduate & Left MCA territory \\
\hline 4 & female & 49 & graduate & Multiple infarct in parieto-occipital cortex \\
\hline 5 & male & 70 & postgraduate & $\begin{array}{l}\text { Multifocal lacunar infarct, left MCA infarct, } \\
\text { deep white matter infarct }\end{array}$ \\
\hline 6 & female & 25 & secondary & $\begin{array}{c}\text { Left parieto-temporal and perisylviancortex, } \\
\text { left MCA }\end{array}$ \\
\hline 7 & male & 47 & illiterate & $\begin{array}{l}\text { Left fronto-temporo-parietal infarct, } \\
\text { left MCA }\end{array}$ \\
\hline 8 & male & 35 & primary & Left MCA, fronto-temporo-parietal \\
\hline 9 & male & 29 & primary & Hemorrhagicinfact in left MCA \\
\hline 10 & male & 59 & graduate & Left temporo-parietal \\
\hline 11 & male & 70 & postgraduate & Diffuse cortical atrophy, MCA infarct \\
\hline 12 & male & 62 & graduate & Embolism in left MCA \\
\hline 13 & male & 59 & graduate & Left MCA infarct \\
\hline 14 & male & 22 & higher secondary & $\begin{array}{l}\text { Multiple infarct in frontal, parietal, } \\
\text { occipital lobes }\end{array}$ \\
\hline 15 & male & 29 & primary & Left parietal \\
\hline 16 & male & 39 & graduate & Left frontal parietal, internal capsule \\
\hline 17 & female & 49 & graduate & MCA infarct \\
\hline 18 & female & 35 & graduate & Multiple infarct in MCA territory \\
\hline 19 & female & 79 & graduate & White matter lesion \\
\hline 20 & male & 23 & graduate & Fronto-temporo-parietal \\
\hline 21 & female & 52 & secondary & PCA and MCA infarct \\
\hline 22 & male & 69 & postgraduate & Diffuse infarct \\
\hline 23 & male & 61 & secondary & Left temporo-parietal \\
\hline 24 & male & 51 & graduate & MCA infarct \\
\hline 25 & female & 32 & secondary & Large infarct in MCA territory \\
\hline 26 & male & 61 & graduate & Diffuse cortical atrophy \\
\hline 27 & female & 72 & secondary & Fronto-temporal hemorrhage \\
\hline 28 & male & 28 & primary & $\begin{array}{l}\text { Multiple infarct in MCA territory, } \\
\text { lacunar infarct }\end{array}$ \\
\hline 29 & male & 55 & graduate & PCA and MCA infarct \\
\hline 30 & male & 73 & postgraduate & MCA infarct, diffuse perisylvian infarct \\
\hline
\end{tabular}


50 years, 51 to 60 years, 61 to 70 years. All the participants were native Bengali speakers and had formal education of 14.25 years +1.65 . The participants consisted of 75 males and 75 females with equal gender distribution in each group. The participants were screened to rule out the presence of any neurological, psychological or speech and language impairments.

The test group consisted of 30 aphasics who had reported to the clinic after a single attack of cerebrovascular accident (CVA). The medical diagnosis of CVA or a neurological insult was confirmed by a neurologist. The site of lesion was confirmed for all the cases by CT scan or MRI. All the participants were native Bengali speakers. The cases were in the ages ranging between 19-78 years, with a mean age of 51.6 years. The most frequent infarcts seen in these cases were in the left MCA territory. The details of the participants in the aphasic group are summarized in Table 1. Participants in both the groups consented to be a part of the study; in the individuals with aphasia, written consent was obtained from a family member or spouse.

The study was conducted in the following four phases:

Phase 1. Development of the test

Phase 2. Adaptation and validation of the WAB (Kertesz, 1982) in Bangla.

Phase 3. Administration of the developed test material on the normal population to establish age-specific normative values and test-retest reliability of the adopted test

Phase 4. Checking the discriminant validity

\section{Phase 1. Development of the test}

The Western Aphasia Battery-Bengali Version, i.e. B-WAB which was developed, is similar in line to the original $\mathrm{WAB}$, and the adaptation was performed taking into account the guidelines of the International Test Commission (2010). The B-WAB consists of subtests evaluating four oral language areas: spontaneous speech, auditory comprehension, repetition, and naming; two written language areas: reading and writing; and four other cognitive abilities: praxis, construction, visuo-spatial ability, and calculation. Under each subtest, materials were developed in Bengali. These materials were a translation of the WAB-English version by following the Brislin methodology of cross-cultural translation (1970). However, some of the items were modified based on the frequency of occurrence of the word, the relative ease or difficulty of pronouncing the words and the grammatical forms to fit the linguistic profile of the Bangla language and the cultural context. The developed test items were rated by five experienced speech language pathologists (who had at least five years of experience each) for familiarity in a binary rating scale where ' 1 ' indicated familiar and ' 0 ' indicated unfamiliar. The items rated 'unfamiliar' were replaced by familiar ones, and the final test consisted of familiar items only.

The items of the original WAB had to be changed in some of the subtests. However, the complexity of the original stimuli was maintained as far as practicable. Some of the changes are given below. 
In the 'spontaneous speech' subtest, the stimulus picture was modified due to the consensus that the original version was culturally inappropriate. Specifically, a garage in a beach-front house and Western dressing style is hardly found in this region. The revised picture had the same thematic content and contained an equal number of objects (i.e. nouns) and actions (i.e. verbs) so that it could elicit the same enumeration as the original.

In the auditory comprehension subtest, sentences were changed according to Bengali syntactic rules. For example, when translating the original sentence "Do ${ }^{1}$ you $^{2}$ live ${ }^{3}$ in $^{4}$ Windsor ${ }^{5}$ ?" into Bengali, it was imperative to change the order of some words, as Bengali observes a subject-object-verb order. In this case, the sentence order was changed through transposition and omission of some words, resulting in "You ${ }^{1} \mathrm{do}^{2}$ Windsor ${ }^{3}$ live $e^{4}$ ?", but here again the word 'Windsor' refers to a city in Canada, which was not familiar, thus it was replaced with '(/birbhum/)', which is a district in West Bengal. Thus the final sentence being developed is /

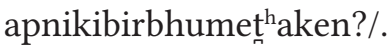

In the naming subtest, there were certain culturally inappropriate words which were also replaced. For example, Bengali people rarely use 'Scotchtape'. Therefore the item '/at ${ }^{\mathrm{h}} \mathrm{a} /$ ' was included instead. In the reading subtest, the original stimuli were replaced with Bengali stimuli having almost the same sentence length and complexity. Sentence meaning was preserved as far as practicable. However, some words and expressions had to be altered to render the sentences culturally appropriate, so that the test could elicit the same enumeration as the original(e.g. /pulifer//kat/e//bonduk//thake/). In the spelled word recognition subtest, the stimuli were replaced with Bengali stimuli having the same number of graphemes (ligature considered) as the original items. Since the writing systems of the two languages are very different, the English words were replaced with Bengali words having asimilar complexity level. For example, /pond/ was substituted with the word / $5 \mathrm{kto} /$ to pressure the complexity of having a double consonant cluster.

Finally, in the writing subtest, stimulus words were selected and replaced based on the number of syllables and familiarity. Besides that, in the sub-section "Alphabets and Writing" scoring as per the original WAB was difficult, since the examiner faced the problem of there being 52 letters in the Bengali alphabet (Thompson, 2006) whereas in English there are only 26 letters. Other areas measuring cognitive abilities retained the same items as the original WAB since the items were not different cross-linguistically.

\section{Phase 2. Validation of the developed test tool}

To validate the developed test tool, both the WAB and B-WAB was administered to 30 normal bilingual subjects. These participants were between the ages of 18 and 30, with a mean education of 12.5 years. All the participants had been exposed to English and Bengali since five years of age, and had received 
formal instruction in English and Bengali for at least 10 years in school. None of the participants had any sensory, motor, cognitive or language impairment, and they belonged to the middle socioeconomic strata. During testing, the WAB and the $\mathrm{B}-\mathrm{WAB}$ were administered with a gap of one week between each test. The responses to each were recorded and the results yielded the validity of the test items.

\section{Phase 3. Administration of the developed test material to the normal population to establish age-specific normative values}

The developed test material was administered to 150 healthy normal individuals between the ages of 18 and 70 years, stratified into five groups based on age ranges: $18-30$ years (mean: 24.78, SD 3.42), 31-40 years (36.9, SD 3.18), 41-50 years (44.43, SD 4.29), 51-60 years (53.2, SD 2.66), 61-70 years (55.54, SD 3.67). There were 71 females and 76 males in the group. The participants were asked to answer the questions as accurately as possible. The time taken to complete the B-WAB was approximately 40-45 min. The same was repeated after one week to check for test-retest reliability and the results revealed good correlation between the test and retest conditions. The average formal education level was 14.5 years +2.9 years. All the participants were native speakers of Bengali.

\section{Phase 4. Establishing discriminant validity}

The test was administered to adults with aphasia with definite brain lesions and language problems (experimental group).

The data obtained from the participants was fed into Microsoft Office Excel 2007, and then the following statistical analyses were conducted using the Statistical Package for Social Sciences (SPSS), version 17.0.

\section{Results}

The validity of the test was evaluated in the second phase by comparing the $\mathrm{WAB}$ and $\mathrm{B}-\mathrm{WAB}$ scores using the paired $t$ test. The results revealed that no significant difference exists between the performance of the participants between the WAB and B-WAB across all the subtests ( $p>0.05)$, as is evident in Table 2. Also Pearson's product moment correlation was performed on the WAB and B-WAB and shows a positive correlation between the scores of different subsections of the $\mathrm{WAB}$ and $\mathrm{B}-\mathrm{WAB}$.

Normative scores were evaluated for different age and gender on all parameters of the B-WAB (e.g. spontaneous speech, auditory comprehension, repetition, naming, reading, writing, praxis, constructional, visuo-spatial and calculation tasks, AQ). The mean scores of the primary language skills did not reveal any significant difference across the age groups. The following table shows the mean values obtained in each age group (Table 3). 
Table 2. "Paired $t$ test" and correlation between the B-WAB and the original WAB

\begin{tabular}{lcccc}
\hline Subtests & T & df & P & $\begin{array}{c}\text { Correlation } \\
(\mathrm{r})\end{array}$ \\
\hline $\begin{array}{l}\text { Spontaneous speech } \\
\text { Content }\end{array}$ & 9 & & 1 \\
Fluency & & & 1 \\
Auditory Comprehension & -0.340 & 9 & 0.741 & 0.983 \\
Repetition & 1.103 & 9 & 0.299 & 0.963 \\
Naming & 0.000 & 9 & 1.000 & 0.954 \\
Reading & -1.369 & 9 & 0.204 & 0.788 \\
Writing & -1.000 & 9 & 0.343 & 0.866 \\
Praxis & -1.000 & 9 & 0.343 & 0.967 \\
Construction & & 9 & & 0.863 \\
Aphasia Quotient(AQ) & 0.924 & 9 & 0.380 & 0.966 \\
\hline
\end{tabular}

Table 3. Mean score of primary language skills and AQ

\begin{tabular}{lccccc}
\hline Subtest & \multicolumn{5}{c}{ Age } \\
& $18-30$ yrs. & $31-40$ yrs. & $41-50$ yrs. & $50-60$ yrs. & $61-70$ yrs. \\
\hline $\begin{array}{l}\text { Spontaneous } \\
\text { Speec } \\
\text { (Total Score = 20) }\end{array}$ & 20 & 20 & 20 & 19.9 & 19.75 \\
$\begin{array}{l}\text { Auditory } \\
\text { Comprehension } \\
\text { (Total Score = 200) }\end{array}$ & 198.45 & 198.2 & 197.45 & 196.95 & 196.15 \\
$\begin{array}{l}\text { Repetition } \\
\text { (Total Score=100) }\end{array}$ & 98.9 & 99 & 99.2 & 98.8 & 97.8 \\
$\begin{array}{l}\text { Naming } \\
\text { (Total Score = 100) }\end{array}$ & 99.65 & 98.85 & 99.1 & 99.25 & 98.75 \\
AQ & 99.54 & 99.38 & 99.40 & 99.09 & 98.41 \\
\hline
\end{tabular}

For secondary language skills, the mean scores and standard deviations were calculated across age and the results are given in Table 4. No significant difference was observed between the groups across the tasks.

Once the normative scores were obtained, the B-WAB was administered to 30 aphasics with predominant stroke in the left MCA region. Table 5 shows the 
Table 4. Mean scores of secondary language skills

\begin{tabular}{lcccc}
\hline $\begin{array}{l}\text { Subtest } \\
\text { Age }\end{array}$ & $\begin{array}{c}\text { Reading (100) } \\
\text { Mean score }\end{array}$ & $\begin{array}{c}\text { Writing (100) } \\
\text { Mean score }\end{array}$ & $\begin{array}{c}\text { Praxis (60) } \\
\text { Mean score }\end{array}$ & $\begin{array}{c}\text { Const \& Cal (100) } \\
\text { Mean score }\end{array}$ \\
\hline $18-30$ & $95.6(6.82)$ & $96.4(3.82)$ & $59.70(0.89)$ & $89.60(6.01)$ \\
$31-40$ & $94.3(7.77)$ & $96.3(3.53)$ & $59.55(1.07)$ & $88.90(6.70)$ \\
$41-50$ & $94.2(7.90)$ & $96.3(4.99)$ & $59.70(0.89)$ & $88.25(6.13)$ \\
$51-60$ & $94.4(7.63)$ & $96.0(4.99)$ & $59.55(1.07)$ & $88.45(6.40)$ \\
$61-70$ & $92.1(8.06)$ & $92.5(6.56)$ & $59.40(1.52)$ & $85.05(6.33)$ \\
\hline
\end{tabular}

Table 5. Mean and standard deviation of the primary subtests of the WAB

\begin{tabular}{lcccc}
\hline & $\begin{array}{c}\text { Spontaneous } \\
\text { Speech }\end{array}$ & $\begin{array}{c}\text { Auditory } \\
\text { Comprehension }\end{array}$ & Repetition & Naming \\
\hline Aphasics & $8.166(5.01)$ & $117.63(41.10)$ & $29.19(12.65)$ & $22.26(19.14)$ \\
Control & $19.65(0.11)$ & $197.43(0.93)$ & $98.74(0.54)$ & $99.12(0.35)$ \\
\hline
\end{tabular}

mean scores across all the primary subtests in the aphasic population and the mean scores for the control group.

To compare the means in all the primary subtests in aphasics and control groups, the test was performed, and the results revealed significant differences in means across the normal and aphasic groups $(p>0.05)$. Thus the tool was found to be successful in distinguishing the aphasic from the normal population.

The results of the primary language skills which are essential for determining the type of aphasia are summarized in Table 6. Based on the computation of the raw scores, the aphasics can be classified according to their characteristics. Hence, it is evident from the table that the B-WAB can discriminate between types of aphasia as effectively as the original WAB.

\section{Discussion}

The results of the present study reveal that the B-WAB is a valid tool and no significant difference exists between the original WAB and the B-WAB, hence it can be used as a clinical tool for evaluating persons with aphasia. No significant difference exists between the performance of the participants between the WAB and $\mathrm{B}-\mathrm{WAB}$. This is indicative of the fact that there is a high positive correlation between the B-WAB and WAB. Unlike reliability coefficients, there is no established criterion for the strength of the validity coefficient. Coefficients as low as 
Table 6. Raw scores of the aphasic participants in primary language characteristics

\begin{tabular}{|c|c|c|c|c|c|}
\hline & Fluency & $\begin{array}{c}\text { Auditory } \\
\text { Comprehension }\end{array}$ & Repetition & Naming & Diagnosis \\
\hline 1 & 8 & 164 & 84 & 36 & Anomic aphasia \\
\hline 2 & 2 & 172 & 26 & 3 & Broca's aphasia \\
\hline 3 & 4 & 155 & 10 & 10 & Broca's aphasia \\
\hline 4 & 9 & 163 & 90 & 70 & Anomic aphasia \\
\hline 5 & 3 & 110 & 24 & 45 & Transcortical motor \\
\hline 6 & 3 & 129 & 12 & 0 & Broca's \\
\hline 7 & 2 & 60 & 0 & 0 & Global \\
\hline 8 & 2 & 144 & 0 & 0 & Broca’s \\
\hline 9 & 2 & 162 & 0 & 4 & Broca's \\
\hline 10 & 5 & 61 & 22 & 8 & Wernicke's \\
\hline 11 & 3 & 102 & 24 & 47 & Transcortical motor \\
\hline 12 & 6 & 140 & 26 & 14 & Conduction \\
\hline 13 & 8 & 48 & 12 & 4 & Wernicke's aphasia \\
\hline 14 & 2 & 41 & 6 & 13 & Isolation aphasia \\
\hline 15 & 2 & 137 & 0 & 0 & Broca's \\
\hline 16 & 2 & 157 & 12 & 2 & Broca’s \\
\hline 17 & 7 & 189 & 68 & 5 & Anomic aphasia \\
\hline 18 & 2 & 87 & 1 & 1 & Global \\
\hline 19 & 7 & 165 & 44 & 3 & Conduction \\
\hline 20 & 4 & 123 & 81 & 2 & Transcortical motor \\
\hline 21 & 1 & 43 & 0 & 0 & Global \\
\hline 22 & 7 & 153 & 65 & 3.1 & Anomia \\
\hline 23 & 4 & 137 & 41 & 18 & Broca’s \\
\hline 24 & 5 & 117 & 38 & 28 & Transcortical sensory \\
\hline 25 & 8 & 170 & 62 & 21 & Anomia \\
\hline 26 & 3 & 132 & 18 & 5 & Broca's \\
\hline 27 & 1 & 32 & 0 & 0 & Global \\
\hline 28 & 2 & 138 & 14 & 11 & Broca's \\
\hline 29 & 8 & 172 & 78 & 22 & Anomia \\
\hline 30 & 8 & 166 & 71 & 18 & Anomia \\
\hline
\end{tabular}

0.20 or 0.30 may establish the validity of a measure (Anastasi \& Urbina, 1997). Thus, the B-WAB and the original WAB obtained similar results from BengaliEnglish bi/multilinguals, thereby asserting the validity of the test developed. The 
individual scores across the age groups in normal individuals in each subtest revealed a ceiling effect; this was probably seeing as the task was easy to perform by normal individuals in all the age groups. A slight deterioration (though not significant) was seen in the auditory discrimination and repetition task across age, and this can be explained by a decrease in auditory selective attention abilities with increasing age (Barr \& Giambra, 1990). Tasks like sequential commands in the auditory comprehension subtest and the repetition task largely rely on auditory processing abilities, and hence a slight deterioration with age was not unexpected. No significant difference was seen in naming skills across the age groups. Similar findings have been reported by various authors in other languages, like the Malayalam (Jenny, 1992), Telugu (Pallavi, 2010), Kannada (Chengappa \& Kumar, 2008) and Korean (Kim \& Na, 2010) WAB.

The normative scores in the four remaining subsections of the B-WAB, i.e. reading, writing, apraxia, and constructional, visuo-spatial and calculation tasks, show a mild decline with increasing age, with the greatest decline seen in the age group of 61-70 years. A similar finding has been reported for the adaptation of the WAB in other languages, such as Kannada (Chengappa \& Kumar, 2008) and Korean (Kim \& Na, 2010). Benton, Eslinger \& Damasio (1981) reported that cognitive functions have been known to substantially decline in this normal aging group. This decline can be attributed to reduced psychomotor speed rather than cognitive linguistic decline with increasing age (Rodríguez-Aranda, 2003). The overall AQ showed a slight decrease with age and this is concurrent with prior findings during the adaptation of WAB in other languages, such as Kannada (Chengappa \& Kumar, 2008) and Korean (Kim \& Na, 2010).

The results of the B-WAB administered to the aphasic population showed that the means across all the subtests differed significantly from that of the normal population. Similar findings have been reported for the adaptation of WAB in other languages, such as Malayalam (Jenny, 1992), Telugu (Pallavi, 2010), Kannada (Chengappa \& Kumar, 2008) and Korean (Kim \& Na, 2010). However, since a myriad of symptom were included, with the Broca's type predominating, the overall AQ was found to be significantly low in the aphasics.

\section{Conclusion}

It can be concluded that there is a consistency in performance and the B$\mathrm{WAB}$ is a reliable tool to be used across various contexts. It is proved beyond doubt that the B-WAB differentiates between normal and aphasic performance. It can thus be concluded from this study that the B-WAB can serve as an effective tool for evaluating persons with aphasia, in the age range of 18-70 years, in this part of the country. Further research is needed to study the trend of scores across each subtest, with respect to different types of aphasia and using the same tool. 


\section{References}

Anastasi, A. \& Urbina, S. (1997). Psychological Testing (7th ed.). Upper Saddle River, NJ: Prentice Hall.

Barr, R.A. \& Giambra, L.M. (1990). Age-related decrement in auditory selective attention. Psychology and Aging, 5 (4), 597-599.

Benton, A.L., Eslinger, P.J., \& Damasio, A.R. (1981). Normative observations on neuropsychological test performances in old age. Fournal of Clinical Neuropsychology, 3 (1), 33-42.

Brislin, R.W. (1970). Back-translation for cross-cultural research. fournal of CrossCultural Psychology, 1, 185-216.

Bromley, D.B. (1991). Aspects of written language production over adult life. Psychology \& Aging, 6 (2), 296-308.

Byng, S., Kay, J., Edmundson, A., \& Scott, C. (1990). Aphasia tests reconsidered. Aphasiology, 4, 67-92.

Chapey, R. (1994). Introduction to language intervention strategies in adult aphasia. In R. Chapey (Ed.), Language Intervention Strategies in Adult Aphasia (pp. 3-26). Baltimore, MD: Williams \& Wilkins.

Chengappa, S.K. \& Kumar, R. (2008). Normative \& clinical data on the Kannada version of Western Aphasia Battery (WAB-K). Language in India, 8. Retrieved from http://www.languageindia.com

Goodglass, H. \& Kaplan, E. (1972). The Assessment of Aphasia and Related Disorders. Philadelphia, PA: Lea \& Febiger.

Goodglass, H. \& Kaplan, E. (1983). The Boston Diagnostic Aphasia Examination. Philadelphia, PA: Lea \& Febiger.

Jenny, E.P. (1992). A Test of Aphasia in Malayalam. Unpublished master's dissertation, University of Mysore, India.

Kasher, A., Batori, G., Soroker, N., Graves, D., \& Zaidel, E. (1999). Effects of rightand left-hemisphere damage on understanding conversational implicatures. Brain and Language, 68 (3), 566-590.

Kertesz, A. (1976). Classification of aphasic phenomena. Canadian fournal of Neurological Science, 3, 135-139.

Kertesz, A. (1982). Western Aphasia Battery. Orlando, FL: Grune \& Stratton.

Kertesz, A. \& Phipps, J. (1977). Numerical taxonomy of aphasia. Brain and Language, 4, 1-10.

Kertesz, A. \& Phipps, J. (1980). The numerical taxonomy of acute and chronic aphasia syndromes. Psychological Research, 41, 179-198.

Kim, H. \& Na, D.L. (1999). Normative data on the Korean version of the Boston Naming Test. Journal of Clinical and Experimental Neuropsychology, 21 (1), 127-133.

Kim, H. \& Na, D.L. (2004). Normative data on the Korean version of the Western Aphasia Battery. Fournal of Clinical and Experimental Neuropsychology, 26 (8), 1011-1020. 
LaPointe, L. (2005). Aphasia and Related Neurogenic Language Disorders. Boston, MA: Thieme.

Lomas, J. \& Kertesz, A. (1978). Patterns of spontaneous recovery in aphasic groups: A study of adult stroke patients. Brain and Language, 5, 388-401.

Manly, J.J., Jacobs, D.M., Sano, M., Bell, K., Merchant, C.A., Small, S.A., \& Stern, Y. (1999). Effect of literacy on neuropsychological test performance in nondemented, education-matched elders. Fournal of the International Neuropsychological Society, 5, (3), 191-202.

McNeil, M.R. \& Copland, D.A. (2011). Aphasia theory, models, and classification. In L.L. LaPointe (Ed.), Aphasia and Related Neurogenic Language Disorders (pp. 27-47). New York: Theme Medical.

Murray, L.L. \& Chapey, R. (2001). Assessment of language disorders in adults. In R. Chapey (Ed.), Language Intervention Strategies in Adult Aphasia and Related Neurogenic Communication Disorder (pp. 55-126). Baltimore, MD: Williams and Wilkins.

Pallavi, M. (2010). Development of Western Aphasia Battery in Telugu. Unpublished master dissertation, University of Mysore, India.

Porch, B.E. (1981). Porch Index of Communicative Ability. Palo Alto, CA: Consulting Psychologists Press.

Rodríguez-Aranda, C. (2003). Reduced writing and reading speed and age-related changes in verbal fluency tasks. The Clinical Neuropsychologist, 17 (2), 203-215.

Sarno, M.T. (2002). Aphasia. In V.S. Ramachandran (Ed.), Encyclopedia of the Human Brain. Volume 1 (pp. 181-192). Academic Press: San Diego.

Schuell, H. (1972). The Minnesota Test for Differential Diagnosis of Aphasia. Minneapolis: University of Minnesota Press.

Thompson, H.R. (2006). Bengali. In K. Brown \& S. Ogilvie (Eds.), Concise Encyclopaedia of Languages of the World (pp. 148-150). Oxford: Elsevier.

WAB Aphasia Test Construction Committee (1986). The fapanese Version of the Western Aphasia Battery. Tokyo: Igaku-Shoin.

Zaidel, E., Kasher, A., Soroker, N., Batori, G., Giora, R., \& Graves, D. (2000). Hemispheric contributions to pragmatics. Brain and Cognition, 43 (1/3), 438-443. 